\title{
Effectiveness of an HIV Prevention Program for Women Visiting Their Incarcerated Partners: The HOME Project
}

\author{
Olga Grinstead Reznick • Megan Comfort • \\ Kathleen McCartney • Torsten B. Neilands
}

Published online: 12 August 2010

(c) The Author(s) 2010. This article is published with open access at Springerlink.com

\begin{abstract}
Having an incarcerated partner presents a unique HIV risk for women, particularly low-income women of color. We developed a population-specific risk reduction intervention for women visiting men in prison that was peer educator-based and included individual and community-level intervention components. Women who were assessed prior to the intervention period had a positive association between the number of unprotected penetrative intercourse (UPI) episodes prior to their partners' incarceration and the number of UPI episodes following partners' release from prison. However, this association was negated among women assessed during the intervention. Intervention participants also were more likely to be tested for HIV, to have partners who got tested, and to talk with their partners about significantly more HIV-related topics. Conducting intervention and evaluation activities with women visiting incarcerated men is feasible and is a useful model for reaching more at-risk women.
\end{abstract}

Keywords Women · Prevention · Prisons - Sexual communication

O. Grinstead Reznick · M. Comfort $(\bowtie) \cdot$ K. McCartney •

T. B. Neilands

Center for AIDS Prevention Studies, University of California,

San Francisco, 50 Beale Street, Suite 1300,

San Francisco, CA 94105, USA

e-mail: megan.comfort@ucsf.edu

K. McCartney

e-mail: mccartneyk@epi-center.ucsf.edu

\section{Introduction}

Women in the United States, particularly low-income women of color, are at increased risk of HIV infection $[1,2]$. Women's gender-specific vulnerabilities to HIV infection include disparities in social opportunity and interpersonal power, and physiological factors [3, 4]. In response to the increasing burden of new HIV infections among low-income women of color, HIV prevention interventions have been developed to address the unique risks that women face $[5,6]$. However, there continue to be contexts of risk that have not been addressed by interventions to date which may be key to targeting HIV prevention interventions to the most vulnerable women. Making interventions relevant, accessible, and feasible within the contexts of women's daily lives may be an effective approach to reduce the disproportionate impact of HIV on women, especially low-income women of color.

One such context is having an incarcerated male partner. The US has the highest per capita incarceration rate in the world [7]. Currently, there are 2.4 million people incarcerated in the United States [8, 9] and 15 million people are processed by the US correctional system each year [10]. At the end of 2008, $1.5 \%$ of state and federal prisoners were reported to be HIV positive or have AIDS [11]. Prisoners are at increased risk for exposure to HIV and other infectious diseases, and in most US prisons, distributing condoms or sterile injection equipment is prohibited. Incarceration disproportionately impacts men of colormales constitute $93 \%$ of prisoners in the United States; $41 \%$ of male prisoners are African American and $20 \%$ are Latino [12].

During her partner's incarceration, a woman is also at increased risk for HIV infection since the couple's separation increases her likelihood of concurrent partners 
$[13,14]$ and financial and psychological stresses increase her risk for unprotected penetrative sexual intercourse (UPI) and needle sharing [15-17]. Post-incarceration, couples may be motivated to engage in UPI in order to demonstrate loyalty, reestablish intimacy, or conceive children [18].

While some HIV prevention literature has focused on the risk of women's incarceration [19, 20], females account for a small proportion of prisoners in the United States. By comparison, millions of women in the United States are likely to be affected by having an incarcerated partner or a partner who was recently released from a correctional facility. Various studies estimate that $50 \%$ of incarcerated men consider themselves to be in committed heterosexual relationships, and intend to return to their partners after release [21-24].

There is a body of literature describing the experience of prisoners' wives and families, including the prison visiting experience (see, for example, [22, 25-31]). Researchers have addressed the community and family consequences of mass incarceration on employment, housing, disenfranchisement, and the breakdown of social control in neighborhoods [32-36]. However, these publications have not focused on HIV risk, although the public health impact of HIV risk for women with incarcerated partners is dramatic. There is great potential in using prison visiting as an opportunity to reach women at risk.

Our research team and Centerforce (a community-based organization that has provided services to prisoners and their families since 1975) began collaborating in 1993 to design and evaluate HIV prevention interventions for incarcerated men and their female partners. Our previous work with male prisoners included the development and evaluation of a peer-led HIV education orientation for arriving prisoners [37], a pre-release intervention for men leaving prison [38, 39], a health promotion intervention for HIV-seropositive prisoners preparing for release [40, 41], and a multi-site HIV, sexually transmitted disease (STD) and hepatitis intervention for young men preparing for release from prison [42, 43]. Early in the course of these studies, men requested HIV-prevention interventions specifically tailored to the needs of their women partners as a way of promoting risk reduction behaviors within the couple. In response, we conducted formative research with women visiting incarcerated men and then piloted a singlesession, population-specific, peer-led HIV intervention [44].

Our formative work with women visiting incarcerated men indicated that it is feasible to engage women in HIVrelated interventions and research evaluation activities, and that the intervention encouraged women to communicate with others regarding HIV prevention [44]. However, our initial single-session intervention did not have a measurable effect on study participants' HIV risk behavior. We next developed and evaluated a multi-component community-level intervention targeting the specific needs of women with incarcerated male partners: the Health Options Mean Empowerment (HOME) intervention. This report describes the HOME intervention and evaluation procedures and reports the evaluation study outcome.

\section{Methods}

All of our intervention and evaluation activities were conducted at a center for visitors at a northern California medium-sized state prison for men. The center was located just outside the prison gates and operated by Centerforce. All research activities were reviewed and approved by the University of California San Francisco Committee on Human Research.

\section{Formative Research and Comparison Sample}

We conducted qualitative interviews with 20 women visiting male partners who were within 12 months of release from prison and 13 correctional officers who worked in visiting areas at the prison. We also conducted a longitudinal quantitative study exploring the domains of our theoretical model of HIV risk and risk reduction among women with incarcerated partners which considers these factors: misinformation, denial, isolation, relationship pressures, and institutional policies [45]. In the longitudinal study we recruited women from the visiting center ( $N=117)$, conducted face-to-face surveys with them during their partner's incarceration, and conducted a second survey 30 days after his release from custody $(N=99$, $85 \%$ follow-up rate). Participants were remunerated $\$ 20$ for completing the baseline interview and $\$ 40$ for the follow-up interview. Assessment included sexual risk behavior, communication about risk reduction, and service utilization. Findings from the qualitative and quantitative formative research were used to design the HOME intervention and evaluation procedures. The quantitative follow-up survey was used as a comparison sample to test the intervention outcome. Figure 1 illustrates the study design and flow of participants through the study.

\section{Intervention}

The purpose of the HOME project was to design and evaluate an intervention to reduce HIV risk among women with male partners being released from prison. There were two primary components of the intervention. First, we trained women visitors to be peer health educators who could speak with other women visiting men at the prisonand women in the peer educators' home communitiesabout HIV risk reduction, especially the specific risks 
Fig. 1 Flow chart of HOME project participants
Comparison Sample Data Collection

September 2003 - March 2004
Intervention Conducted

Intervention Sample Data Collection

February 2005 - January 2006
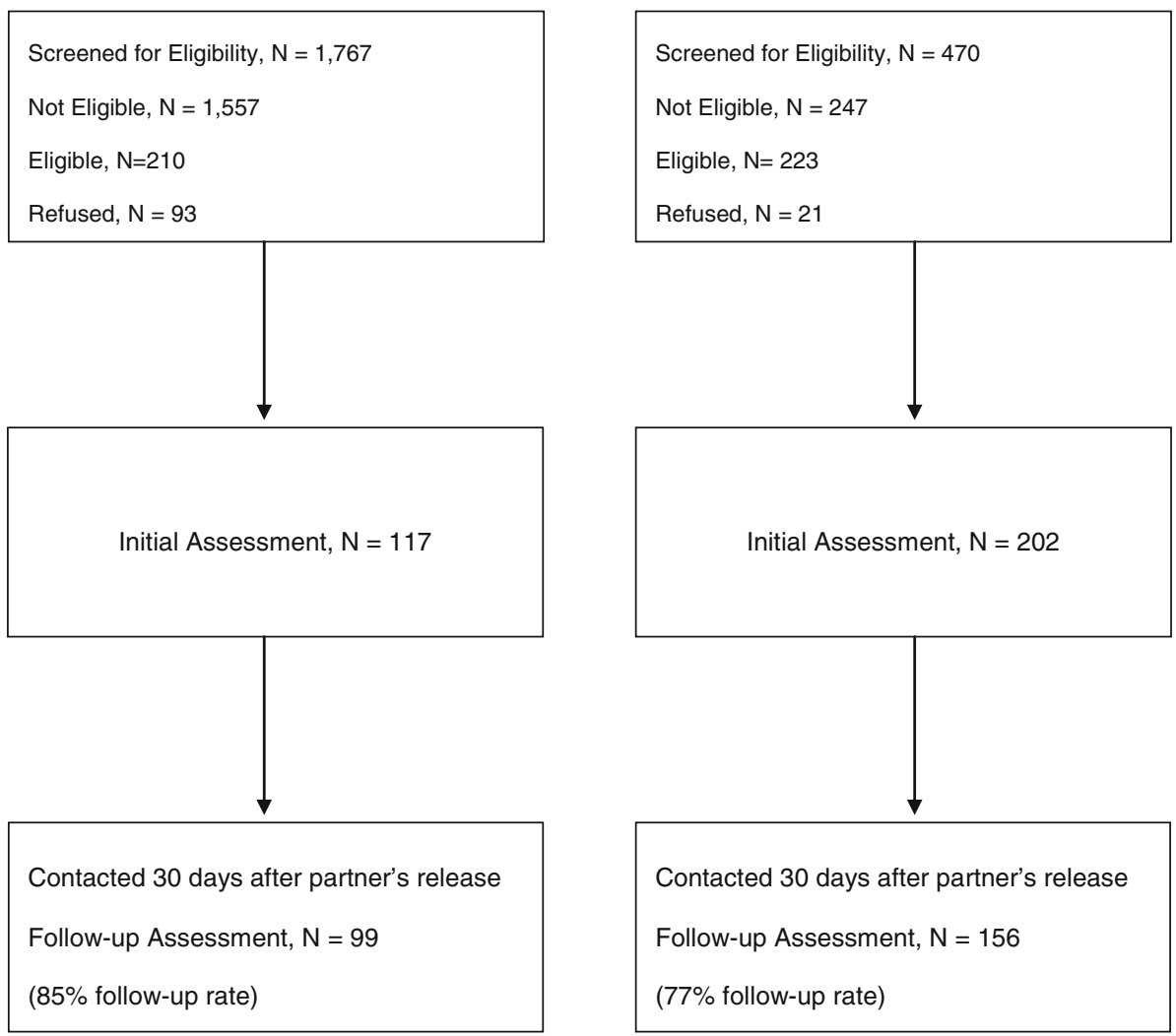

associated with having an incarcerated or recently released partner. The second component consisted of organizing and facilitating a range of community-building activities (i.e. informal lunch gatherings); general-health workshops on a variety of topics, including diabetes, blood pressure, and smoking cessation; workshops on HIV/AIDS and other sexually transmitted infections (STIs); facilitated community referrals, and other services geared specifically to the needs of women who visit men in prison. These activities and workshops were organized by intervention staff members, with input and assistance from the peer educators.

Women visitors therefore had multiple avenues of intervention participation available to them: they could attend workshops and community activities, request a facilitated referral to a service provider in their home neighborhood, talk one-on-one with a peer educator about sexual health concerns and HIV risk reduction, and undergo training to become peer educators themselves. Although the HOME project was designed specifically for the needs of women in romantic or sexual partnerships with incarcerated men, all women who were visiting were invited to participate in the intervention activities. Our decision to include mothers, sisters, friends, and other women who were not visiting romantic partners in intervention activities stemmed from learning in our formative research that women visiting prisoners experience exclusion in many areas of their lives. We chose not to add to these experiences by prohibiting their participation in what was, at the time, the only program in operation for visitors at this prison. We also felt that including all women visitors would facilitate dissemination of HIV prevention information among vulnerable women.

We fielded our intervention from February 2005 through January 2006. The HOME field staff consisted of four women: a peer educator coordinator (PEC), an activities and workshops coordinator, and two research interviewers. During all hours that the prison was open for visiting $(8 \mathrm{~h}$ per day, Thursday through Sunday), HOME project staff 
members were present in the prison visitors' center and the area where visitors wait to enter the prison. HOME staff members would approach women visitors, engage them in conversation, offer information about visiting the prison, tell them about the HOME intervention and evaluation activities, offer services, and recruit eligible visitors to participate in the program.

\section{HOME Peer Educators}

Our formative research with women visiting incarcerated men made it clear that women visitors had many constraints on their time that limited their ability to attend regularly scheduled, multi-component intervention groups. We developed a peer education component for HOME that was designed to encourage maximum participation by adapting training and supervision to each woman's schedule. Staff members informed women visitors about the peer educator program. Women who expressed interest in the training met with the PEC, who explained that participation in the program was open to any interested woman who: was visiting a prisoner, was willing to sign a confidentiality agreement protecting information of other visitors, and agreed to meet with the PEC on a regular basis for training and supervision. Women who accepted these conditions were scheduled for a peer educator orientation session. Upon completion of this session the woman was considered to be a HOME peer educator and began receiving bi-monthly reimbursements of $\$ 50$; there were no formal requirements for receiving these reimbursements other than maintaining contact with the PEC. During the 1-year intervention period, 14 women completed the orientation session to be peer educators.

The PEC held a weekly individual supervision session with each peer educator in person or by phone during which the peer educators provided an update on their outreach activities, received feedback from the PEC on any questions or issues that arose during outreach, and set goals for future outreach and training. Thirteen of the women who completed an orientation session remained in at least bi-monthly contact with the PEC and 1 was lost to follow-up after the orientation session. Peer educators continued to receive training sessions as their time permitted. Peer educators who completed a series of six training sessions were presented with a certificate of completion. During the intervention period, 2 women completed all six sessions and the remaining 11 participated in multiple training activities. The six training sessions covered: (1) orientation to the HOME Project; (2) viewing and discussing Inside/Out, a film featuring formerly incarcerated men and the female partners of inmates discussing prison-specific HIV risk and couple communication issues; (3) HIV/AIDS and hepatitis $\mathrm{C}$ virus (HCV) information; (4) facilitating referrals and providing resources; (5) community-building skills; and (6) outreach skills. Training sessions were provided oneon-one or in small groups, depending on women's availability, and followed interactive formats utilizing role plays, hands-on skills building, and discussions. Further detail on the peer-educator training program and HOME project intervention activities is provided in Grinstead et al. [45].

All peer educators were encouraged to provide HIV risk reduction information to women in their home communities as well as to other women visitors. Although peer educators were not systematically selected or screened, the primary cities of the area (San Francisco, Oakland, and Richmond) were represented. These cities represent major population hubs for the nine counties that constitute the greater San Francisco Bay Area.

\section{HOME Intervention Activities}

Since one of our intervention goals was to link women to resources in their residential neighborhoods, many of our activities involved inviting a speaker or outreach worker from a community-based organization or local service provider to give a presentation, talk one-on-one with visitors, and distribute information about available services. Speaker activities occurred on average once per week. Speakers included nurses, nutritionists, legal aid consultants, and inspirational speakers who described their experiences coping with incarceration or the incarceration of a loved one.

In addition to this series of featured speakers, the HOME project organized a health fair that was held in the prison visitors' parking lot on a weekend visiting day. Representatives from eight community-based health and social service organizations distributed literature and materials, answered questions, and provided referrals to all visitors entering and leaving the prison that day. During the health fair, free acupuncture, yoga instruction, and refreshments were provided.

When an outside speaker was not present, the HOME intervention staff and any available peer educators conducted small-scale activities such as demonstrations of male and female condoms, discussions of women's health concerns, or coaching on how to write letters to politicians or prison officials to advocate for incarcerated loved ones. Such activities were provided daily, with the intervention staff members choosing the activity in response to the needs or interests of the visitors who were present. The intervention staff members also were continually available for one-on-one discussions with women who wanted to talk in private; these conversations typically resulted in the HOME staff member making facilitated referrals to services in the women's communities. In addition, lunch was provided each Friday as another opportunity to recruit women to the intervention and provide referrals and support. All HOME activities were free and required no 
advance registration; participants in HOME activities were not remunerated.

\section{Intervention Evaluation}

We collected data during the intervention period using the same procedures and quantitative surveys that we had used for the comparison survey during the formative research period. We recruited 202 participants for the first survey, and 156 completed the follow-up survey 30 days after their partner's release from custody ( $77 \%$ follow-up rate). As with the comparison sample, participants were remunerated \$20 for completing the baseline interview and $\$ 40$ for completing the follow-up interview. The first survey measured behavior in the 30 days prior to the participant's partner's incarceration, and the second survey measured behavior during the 30 days following the partner's release from prison. Intervention outcome was assessed by comparing the follow-up surveys conducted with women who had participated before the intervention was initiated (the comparison sample), and the follow-up surveys conducted with women who had participated during the intervention period (the intervention sample). We chose this intervention design to focus on postrelease sexual behavior, which is the key element in risk experienced by women with incarcerated partners. Eligibility criteria included being at least 18 years of age and visiting a husband or boyfriend who would be released prior to the end of the intervention period.

Women recruited for the surveys were taken to a private interview space at the visiting center. The initial survey was administered face-to-face by a trained female interviewer and required approximately $60 \mathrm{~min}$. The second interview was conducted in person or via telephone. Surveys included questions about sexual risk behavior, HIV testing, and communication about HIV risk and risk reduction. Respondents were asked about the occurrence and frequency of sexual intercourse and condom use. HIV testing was assessed by asking respondents if they or their partner had been tested in the time since the participant's initial interview. Respondents were also asked if they had talked to their partner about a series of topics, including HIV risk behavior in prison, HIV testing, and sex with other partners. For each topic, survey questions addressed whether the respondent had wanted to talk with her partner about the topic, and whether she had actually discussed the topic with her partner (e.g. Did you want to talk with your partner about HIV testing? Did you talk to your partner about HIV testing?). In the intervention sample follow-up survey, respondents were asked if they had attended any HOME intervention activities, and if so, how many activities they had attended.

Finally, all women who completed the peer education orientation and at least one supervision session were invited to participate in a qualitative interview $(N=11)$ and a 3-month follow-up interview $(N=9)$. Findings from these interviews have been published separately [45].

\section{Data Analysis}

SAS 9.1.3 was used to compute one-way frequency tables, measures of central tendency, and two-way cross-tabular tables and test statistics (e.g., Fisher's exact test). Continuous variables were compared across the formative and intervention samples via independent sample $t$-tests; ordinal variables were compared via the score statistic. Nominal variables in $2 \times 2$ tables were compared using Fisher's exact test. Nominal variables with more than two levels were compared using exact statistics derived from Monte Carlo simulations.

To evaluate the impact of the HOME intervention on sexual risk behavior, we compared frequencies of UPI at follow-up across the comparison and intervention samples while controlling for pre-incarceration rates of UPI. Main effects for participant sample (comparison sample vs. intervention sample), pre-incarceration UPI, and their interaction were evaluated. UPI was defined as the sum of reported unprotected vaginal intercourse acts and unprotected anal intercourse acts. Because the follow-up UPI contained frequency counts, these counts were analyzed using zero-inflated negative binomial (ZINB) regression. Zero-inflated models contain a mixture of two model components: (i) a logistic component that models the odds of a participant's response always being zero versus not always zero and (ii) a negative binomial component that models the participant's mean count on the log scale. Coefficients from the logistic component of the model can be exponentiated to obtain an odds ratio of being in the always zero group versus not being in the always zero group per unit change in the explanatory variable. The coefficients from the negative binomial component of the model can be exponentiated to obtain an incidence rate ratio (IRR) representing the factor change in the mean count of the outcome per unit change in the explanatory factor [46]. Significant interactions between baseline UPI levels and sample membership were explored by generating within-group odds ratios and IRRs of the regression post-release UPI onto pre-release UPI. The ZINB analysis was performed using Stata 9.1 [47]. Inference was performed using robust standard errors.

\section{Results}

\section{Demographics}

Table 1 describes participant demographic characteristics. Most participants were African American women who 
Table 1 Baseline characteristics of comparison and intervention samples

\begin{tabular}{|c|c|c|c|c|c|}
\hline $\begin{array}{l}\text { Sample } \\
\text { Variable }\end{array}$ & $\begin{array}{l}\text { Comparison } \\
N(\%)\end{array}$ & $\begin{array}{l}\text { Intervention } \\
N(\%)\end{array}$ & $\begin{array}{l}\text { Total } \\
N(\%)^{\text {a }}\end{array}$ & $\chi^{2}(\mathrm{DF})$ & $P$ \\
\hline Total & $117(100)$ & $202(100)$ & 319 & & \\
\hline Relationship status & & & & $4.99(4)$ & 0.29 \\
\hline Legally married & $44(38)$ & $57(28)$ & $101(32)$ & & \\
\hline Engaged & $28(24)$ & $52(26)$ & $80(25)$ & & \\
\hline Committed relationship, unmarried & $42(36)$ & $80(40)$ & $122(38)$ & & \\
\hline Dating & $3(3)$ & $11(6)$ & $14(4)$ & & \\
\hline Other & $0(0)$ & $2(1)$ & $2(1)$ & & \\
\hline Ethnicity & & & & $4.06(4)$ & 0.39 \\
\hline African-American & 45 (39) & $89(44)$ & $134(42)$ & & \\
\hline Latina/Hispanic & $15(13)$ & $32(16)$ & $47(15)$ & & \\
\hline White & $33(28)$ & $52(26)$ & $85(27)$ & & \\
\hline Mixed & $15(13)$ & $14(7)$ & $29(9)$ & & \\
\hline Native American/Asian/Other & $9(7)$ & $14(7)$ & $23(7)$ & & \\
\hline Speak language other than English & $31(27)$ & $49(25)$ & $80(25)$ & $0.16(1)$ & 0.69 \\
\hline Education & & & & $2.96(2)$ & 0.23 \\
\hline Less than high school & $12(10)$ & $21(11)$ & $33(10)$ & & \\
\hline High school or GED & $33(28)$ & $75(37)$ & $108(34)$ & & \\
\hline More than high school & $72(62)$ & $105(52)$ & $177(56)$ & & \\
\hline Currently taking classes & $28(24)$ & $46(23)$ & $74(23)$ & $0.04(1)$ & 0.89 \\
\hline Annual income level & & & & $24.21(5)$ & $<0.01$ \\
\hline Less than $\$ 10,000$ & $26(22)$ & $32(16)$ & $58(18)$ & & \\
\hline$\$ 10,001-\$ 20,000$ & $30(26)$ & $45(22)$ & $75(24)$ & & \\
\hline$\$ 20,001-\$ 30,000$ & $30(26)$ & $37(18)$ & $67(21)$ & & \\
\hline$\$ 30,001-\$ 40,000$ & $17(15)$ & $21(11)$ & $38(12)$ & & \\
\hline More than $\$ 40,000$ & $12(10)$ & $25(12)$ & $37(12)$ & & \\
\hline Do not know/refused & $2(1)$ & $41(20)$ & $43(14)$ & & \\
\hline Resident of a local county ${ }^{b}$ & $99(85)$ & $168(83)$ & $267(84)$ & $0.11(1)$ & 0.88 \\
\hline Living situation & & & & $6.79(2)$ & 0.03 \\
\hline Apartment (self-paid) & $67(57)$ & $142(71)$ & $209(66)$ & & \\
\hline Apartment (other-paid) & $37(32)$ & $48(24)$ & 85 (27) & & \\
\hline Motel/shelter/homeless/other & $13(11)$ & $11(6)$ & $24(8)$ & & \\
\hline Raising children in home & $66(56)$ & $124(62)$ & $190(60)$ & $0.96(1)$ & 0.35 \\
\hline Previously tested for HIV & $100(86)$ & $182(91)$ & $282(89)$ & $1.90(1)$ & 0.17 \\
\hline Visit prison via public or private transit & & & & $0.15(2)$ & 1.00 \\
\hline Public transit & $10(9)$ & $17(9)$ & $27(9)$ & & \\
\hline Private transit & $101(89)$ & $180(90)$ & $281(89)$ & & \\
\hline Both public and private transit & $3(3)$ & $4(2)$ & $7(2)$ & & \\
\hline Allowed contact visits & $66(56)$ & $106(54)$ & $172(55)$ & $0.25(1)$ & 0.64 \\
\hline Frequency of visiting partner & & & & $5.97(5)$ & 0.31 \\
\hline Four times per week & $3(0)$ & $0(0)$ & $3(1)$ & & \\
\hline Two to three times per week & $25(22)$ & $46(24)$ & $71(23)$ & & \\
\hline Once per week & $57(49)$ & $91(47)$ & $148(48)$ & & \\
\hline Two to three times per month & $20(17)$ & $39(20)$ & $59(19)$ & & \\
\hline Once per month & $8(7)$ & $10(5)$ & $18(6)$ & & \\
\hline Less than once per month & $3(3)$ & $6(3)$ & $9(3)$ & & \\
\hline
\end{tabular}


Table 1 continued

\begin{tabular}{|c|c|c|c|c|c|}
\hline Variable & Mean (SD) & Mean (SD) & Mean (SD) & $t(\mathrm{DF})$ & $P$ \\
\hline Number of days visiting ${ }^{\mathrm{c}}$ & 204.5 (438.7) & $136.0(140.9)$ & $162(293.4)$ & $1.58(121)$ & 0.12 \\
\hline Number of days until partner's release ${ }^{\mathrm{d}}$ & $54.5(36.8)$ & $84.0(68.4)$ & $73.1(60.5)$ & $5.00(314)$ & $<0.01$ \\
\hline Unprotected penetrative intercourse acts ${ }^{\mathrm{e}}$ & $16.3(19.4)$ & $21.6(32.3)$ & $19.6(28.3)$ & $1.81(315)$ & 0.08 \\
\hline
\end{tabular}

${ }^{a}$ Percentages may not sum to 100 due to rounding. Income percentages did not differ across groups when respondents who endorsed "do not know" or "refused" were excluded $\left(\chi^{2}(4)=2.03, P=0.74\right)$

${ }^{b}$ Local counties refer to the nine Bay Area counties: Marin, Sonoma, Alameda, Contra Costa, San Francisco, San Mateo, Santa Clara, Solano, and Napa

${ }^{c} N=287$

${ }^{\mathrm{d}} N=318$

${ }^{\text {e }} N=317$

lived within a 50 miles radius of the prison. The most common relationship category was "in a committed relationship but not married" (38\% overall). We assessed for pre-post changes in relationship status between the comparison and intervention groups (decreased commitment, no change, or increased commitment); there were no significant differences between the groups $\left(\chi^{2}(2)=1.44\right.$, $P=0.49$ ). The majority reported income less than $\$ 30,000$ per year, well under the median annual household income level in the area, which is approximately $\$ 60,275$ [48].

The demographic characteristics of the comparison and intervention samples were generally similar. Only income and living situation exhibited statistically significant differences, with a larger proportion of women in the intervention sample living in apartments they paid for. Among respondents who reported their annual income levels, there was no significant difference between the two samples. However, while $2 \%$ of the comparison sample refused to provide (or could not recall) their annual income, this was true of $20 \%$ of the intervention sample. The most common category of visiting frequency was once per week. There were no differences between the two samples in the number of days women had been visiting, but a significant difference in estimated time until the partner's release, with a shorter estimated number of days until release (median $=51$ days $)$ in the comparison sample versus the intervention sample (median $=66$ days; see Table 1 for comparisons of means). This is because the comparison sample was limited to women whose partners would be released within 3 months while the intervention sample included any woman whose partner would be released by the end of the study period.

\section{Unprotected Penetrative Intercourse}

The mean number of UPI acts at baseline in the comparison sample was 16.32 (median $=10)$ whereas the mean number of UPI acts in the intervention group at baseline was 21.56 (median $=10$; see Table 1$)$. The corresponding follow-up mean values of UPI were 20.27 (median $=15$ ) and 17.17 (median $=10$ ) for the comparison and intervention groups, respectively. Table 2 displays the results of the ZINB regression analysis of UPI. No significant effects were found in the logistic component of the model for the odds of engaging in one or more UPI acts versus no UPI acts following the partners' release from prison (all $P$ s $>0.20)$. In the negative binomial component of the model, a significant group-by-pre-release UPI interaction was found, indicating that the effect of pre-release UPI on post-release UPI was different in the comparison and intervention groups. In the comparison group, there was a positive effect of pre-release UPI on post-release UPI

Table 2 Post-intervention findings for unprotected penetrative intercourse (UPI)

\begin{tabular}{lll}
\hline Effect & \multicolumn{2}{l}{ Model component } \\
\cline { 2 - 3 } & Logistic OR (95\% CI) & Negative binomial IRR (95\% CI) \\
\hline Group: Intervention versus comparison & $1.128(0.310,4.105)$ & $1.273(0.856,1.892)$ \\
Baseline UPI & $0.897(0.729,1.103)$ & $1.019(1.010,1.029)^{* *}$ \\
Intervention $\times$ Baseline UPI & $1.065(0.861,1.317)$ & $0.987(0.975,0.998)^{*}$ \\
\hline
\end{tabular}

Results originate from a zero-inflated negative binomial regression analysis conducted in Stata $9.1(N=247)$. Group is coded as $0=$ comparison group member; $1=$ intervention group member. $O R$ odds ratio per unit change in the explanatory variable for always zero class of participants. IRR incidence rate ratio per unit change in the explanatory variable for the not always zero class of participants

$* p<0.05 ; * * p<0.01$ 
$(\mathrm{IRR}=1.019,95 \% \quad \mathrm{CI}=1.010-1.029, \quad Z=4.12, \quad P<$ $0.01)$. The rate for unprotected sex in this group increased by $1.9 \%$ for each unit increase in the number of unprotected sex acts reported at baseline. By contrast, in the intervention group there was no association between prerelease UPI and post-release UPI $($ IRR $=1.006,95 \%$ $\mathrm{CI}=0.999-1.013, Z=1.62, P=0.11)$. The interaction effect shows that these UPI rates are significantly different between the comparison sample and the intervention sample, with the UPI rate being $1.3 \%$ lower per unit increase in baseline UPI in the intervention sample relative to the comparison sample.

Due to the significant differences between the two samples in respondents' income reporting, living situations, and number of days until the partner was released from prison (see Table 1), we also considered extended ZINB models that incorporated these variables plus their interactions with pre-release UPI. Results from these analyses yielded identical substantive inferences, indicating that income level, living situations, and number of days until the partner was released did not modify the relationships presented above.

\section{HIV Testing and HIV-Related Communication}

Table 3 shows results for follow-up HIV testing and HIVrelated communication measures. At their follow-up survey, nearly three times more women in the intervention sample reported having tested for HIV since the time of their initial survey, and more than two times the number of women in the intervention sample reported that their partners had received HIV tests. Regarding HIV-related communication, women in both samples noted that they wanted to talk to their partners about an equal number of HIV risk and risk-related topics, but women in the intervention sample reported that they actually talked to their partners about more HIV-related topics after the partners' release from prison.

\section{Exposure to HOME Intervention Activities}

Intervention sample respondents were asked if they had attended any HOME project activities, and $25 \%$ of respondents reported attending at least one activity. Of those, $33 \%$ attended one activity, $16 \%$ attended two activities, $8 \%$ attended three activities, and $42 \%$ attended four or more activities. Comparisons of sexual risk behavior, HIV testing, and sexual communication outcomes between women who attended at least one intervention activity and women who attended no intervention activities were not statistically significant.

\section{Discussion}

Findings of this study provide further evidence that conducting intervention and evaluation activities with women visiting incarcerated men is feasible, and that women respond well to intervention activities that are sensitive and specific to their needs in the context of prison visiting. Women visitors engaged readily with intervention and evaluation staff and participated in a variety of HIV-specific and more general intervention activities, as well as indepth quantitative interviews. Women visitors were also willing to participate in delivering the intervention as peer educators; the feasibility of a peer education model in this setting is particularly encouraging, given that peer-based programs are cost-effective and particularly useful in contexts where the target population is culturally or linguistically specific [38, 49].

The HOME project helped reduce women's HIV risk in three main areas. First, study findings suggest that the intervention had an impact on HIV risk behavior. Women who were assessed prior to the introduction of the intervention had a significant positive association between rates of risk behavior before and after their partner's release. By contrast, after the intervention was in place, pre-intervention and post-intervention risk were unrelated. Given the

Table 3 Post-intervention findings for HIV testing and sexual communication

\begin{tabular}{|c|c|c|c|c|c|}
\hline Sample & Comparison & Intervention & Test statistic & Test statistic value & $P$ \\
\hline \multicolumn{6}{|l|}{ Variable } \\
\hline HIV testing $(N ; \%)$ & $13(13)$ & $52(34)$ & $\chi^{2}(\mathrm{DF})$ & $13.44(1)$ & $<0.01$ \\
\hline Partner tested for HIV $(N ; \%)$ & $13(18)$ & $48(39)$ & $\chi^{2}(\mathrm{DF})$ & $9.29(1)$ & $<0.01$ \\
\hline $\begin{array}{l}\text { HIV-related communication: Number of topics } \\
\text { participant wanted to discuss (median) }{ }^{\mathrm{a}}\end{array}$ & 1.00 & 1.00 & Wilcoxon & 11152.5 & 0.60 \\
\hline $\begin{array}{l}\text { HIV-related communication: Number of topics } \\
\text { participant reporting discussing with her partner (median) }\end{array}$ & 1.00 & 2.00 & Wilcoxon & 10357.5 & 0.04 \\
\hline
\end{tabular}

${ }^{\mathrm{a}} N=242$

${ }^{\text {b }} N=234$ 
dynamics of relationship separation and reunion [18], we would expect to see an increased rate of sexual risk in the month following partners' release from prison, and this is indeed what we observed in the comparison sample. However, women who were assessed after the intervention did not increase their rate of sexual risk behavior after their partner's release. Results also suggest improvement in sexual communication. In the intervention sample, women talked to their partners about more HIV-related topics after release. Finally, women who were followed-up after the intervention had been in place were more likely to be tested for HIV - and their partners were more likely to have been tested as well-compared with women who were followedup before the intervention was in place.

Evaluating this community-based intervention presented research design challenges. We conducted in-depth assessments of women visiting their intimate partners during the partner's incarceration and after the partner had been home for 30 days, sampling both before and after the intervention was in place. To evaluate the outcome of the intervention, we analyzed post-release sexual risk behavior as the outcome, and treated pre-incarceration sexual risk behavior as a covariate, rather than establishing the analysis as a pre-post repeated measures analysis. This allowed us to account for each woman's history of risk behavior in the relationship while focusing on the key issue that indicates excess risk in this population-her likelihood of engaging in UPI with her partner after his release from prison. That this evaluation design was feasible and yielded clear results supports the use of creative evaluation designs in community settings where the "gold standard" of a randomized intervention study is not ethical, feasible, or cost-effective.

In the intervention follow-up survey, $25 \%$ of respondents reported they had attended a HOME project activity. Given the positive impact of the intervention on reducing risk behavior, encouraging communication about HIV, and increasing HIV testing, it was surprising that more visitors did not report attending specific intervention activities. One possibility is that the intervention's action was primarily via informal dissemination from peer educators to visitors, or between visitors, more so than via attendance to specific intervention events. Another possibility is that respondents attended the events, but the intervention was so well-integrated into ongoing visitor services that the events were not identified as specific to the HOME project. Future studies of this and other community-level interventions embedded in ongoing community programs might use qualitative interviews with participants to further explore the mechanisms of the intervention's impact and to develop population- and setting-appropriate ways to measure intervention dosage.

Our primary inferential analyses were patterned after intent-to-treat analyses in randomized trials in the sense that all intervention group participants were considered members of the intervention group, regardless of their levels of direct exposure to the intervention. This approach is consistent with the community diffusion model we used to design our intervention because we expected that the intervention's messages would be disseminated to women visitors. These analyses found that women in the intervention sample exhibited more sexual communication, a more stable rate of sexual risk behavior, and increased HIV testing relative to women in the comparison group following the man's release from prison. By contrast, an astreated analysis that defined the intervention group to be comprised of women who reported attending one or more intervention group sessions yielded no statistically significant findings on these outcomes. This result could be due to insufficient statistical power to identify effects of the intervention in this smaller group of participants, or it could be due to other unmeasured factors. Future research is needed to determine which components of the intervention are most efficacious.

While our findings are supportive of the feasibility and effectiveness of the HOME intervention, results should be interpreted with caution due to several limitations of the study. We used convenience samples to conduct this first demonstration of the feasibility and effectiveness of the HOME intervention; a randomized study involving multiple sites will be necessary to further investigate the effectiveness and mechanisms of the intervention. Our study also included limited data on exposure to the intervention. In addition, our study design does not allow us to rule out the possibility that differences between the comparison and intervention groups are due to a cohort effect, as there was a year between the collection of the two samples. However, during that year there were no alterations to the visiting procedures or programs at the prison or visiting center, and the demographics and initial behavior of the two samples were found to be quite similar. Finally, the prison at which this study was conducted is close to an urban center, where it benefits from a high degree of involvement by community-based service providers and the opportunity for frequent visitation. Future studies must determine applicability of this intervention model to geographically isolated prisons where visitors travel long distances, as is increasingly common in California as well as other states.

Our intervention for women with incarcerated partners demonstrated several potentially effective approaches to reaching and engaging women at risk for HIV infection. One of the defining characteristics of the intervention was that it was tailored to the women's context of risk, including the challenges of being separated from her partner, visiting the prison, and the stresses of reunification. Intervention activities were also purposefully low threshold, meaning that women could participate at a variety of 
levels requiring various degrees of commitment, time, and personal disclosure. Other characteristics of the intervention were its inclusiveness in making activities available to all women in the setting rather than restricting it to women visiting an intimate partner, and having a variety of activities that women could engage in even if they were not comfortable discussing HIV prevention directly. Finally, the intervention was characterized by including a peer education component.

In addition, the intervention was the product of a collaboration between university researchers and a community-based service agency with a long history of working with corrections. This model should be considered in efforts to introduce evidence-based HIV prevention programs into correctional settings where there are likely to be access and feasibility issues for both intervention and evaluation activities. Future research might translate our population-specific, community collaborative, multi-component intervention approach to engage at-risk women in other contexts, such as substance abuse treatment centers or women's jails and prisons. Studies might be designed to determine which intervention components could be translated across settings to create effective interventions. We also note that many study participants remarked that the process of responding to the survey questions caused them to reflect on HIV risk in general, and on their own HIV risk behavior. The potential impact of individual attention and of asking at-risk women about contextually-specific behaviors that might put them at risk for HIV and STIs should be considered in our search for innovative intervention approaches for women who may not be aware of their own risk for HIV.

Acknowledgments We would like to thank all of the HOME participants and our funders at the National Institute of Nursing Research (NINR) for their contributions to this project. We would like to acknowledge the HOME Project staff, including Angela Allen, Barbara Garcia, and Christine Soriano (UCSF Center for AIDS Prevention Studies); Jolene Forman, Katie Kramer, Yolanda Najera, Tara Regan, and Barry Zack (Centerforce, Inc.).

Open Access This article is distributed under the terms of the Creative Commons Attribution Noncommercial License which permits any noncommercial use, distribution, and reproduction in any medium, provided the original author(s) and source are credited.

\section{References}

1. Henry J. Kaiser Family Foundation. Women and HIV/AIDS in the United States. Menlo Park, CA: Henry J. Kaiser Family Foundation; 2008.

2. Centers for Disease Control and Prevention. HIV/AIDS among women. Atlanta, GA: Centers for Disease Control and Prevention; 2008.
3. Dawson G. HIV disease and black women. J Natl Med Assoc. 2005;97(10):1449-50.

4. Whitmore SK, Satcher AJ, Hu S. Epidemiology of HIV/AIDS among non-Hispanic black women in the United States. J Natl Med Assoc. 2005;97(7 Suppl):19S-24S.

5. Wingood GM, DiClemente RJ. Enhancing adoption of evidencebased HIV interventions: promotion of a suite of HIV prevention interventions for African American Women. AIDS Educ Prev. 2006; 18:161-70.

6. Romero L, Wallerstein N, Lucero J, Fredine H, Keefe J, O'Connell J. Woman to woman: coming together for positive change-using empowerment and popular education to prevent HIV in women. AIDS Educ Prev. 2006;18(5):390-405.

7. Walmsley R. World population prison list. 8th ed. London: Kings College London; 2009.

8. West H, Sabol J. Prison inmates at midyear 2008—statistical tables. Washington, DC: U.S. Department of Justice; 2009.

9. Minton T, Sabol J. Jail inmates at midyear 2008-statistical tables. Washington, DC: U.S. Department of Justice; 2009.

10. Camp C, Camp G, May B. The 2001 corrections yearbook. Middletown, CT: Criminal Justice Institute; 2002.

11. Maruschak L, Beavers R. HIV in prisons, 2007-08. Washington, DC: U.S. Department of Justice, Bureau of Justice Statistics; 2009.

12. Sabol WJ, Minton TD, Harrison PM. Prison and jail inmates at midyear 2006. Washington, DC: U.S. Department of Justice; 2007.

13. Adimora AA, Schoenbach VJ, Martinson FEA, Donaldson KH, Stancil TR, Fullilove RE. Concurrent partnerships among rural African Americans with recently reported heterosexually transmitted HIV infection. J Acquir Immune Defic Synd. 2003;34(4): 423-9.

14. Johnson RC, Raphael S. The effects of male incarceration dynamics on aids infection rates among African-American women and men: National Poverty Center. 2006. Working paper No: $06-22$

15. Sterk C, Theall K, Elifson K. The impact of emotional distress on HIV risk reduction among women. Subst Use Misuse. 2006;41(2):157-73.

16. Roberts A, Wechsberg W, Zule W, Burroughs A. Contextual factors and other correlates of sexual risk of HIV among African-American crack-abusing women. Addict Behav. 2003;28(3):523-36.

17. Gurung R, Taylor S, Kemeny M, Myers H. 'HIV is not my biggest problem': the impact of HIV and chronic burden on depression in women at risk for AIDS. J Soc Clin Psychol. 2004;23(4):490-511.

18. Comfort M, Grinstead O, McCartney K, Bourgois P, Knight K. 'You can't do nothing in this damn place': sex and intimacy among couples with an incarcerated male partner. J Sex Res. 2005;42:3-12.

19. Freudenberg N. Adverse effects of US jail and prison policies on the health and well-being of women of color. Am J Public Health. 2002;92(12):1895-9.

20. Hammett T, Drachman-Jones A. HIV/AIDS, sexually transmitted diseases, and incarceration among women: national and southern perspectives. Sex Transm Dis. 2006;33(7 Suppl):S17-22.

21. Jorgensen JD, Hernandez SH, Warren RC. Addressing the social needs of families of prisoners: a tool for inmate rehabilitation. Fed Probat. 1986;50:47-52.

22. Carlson BE, Cervera N. Inmates and their families: conjugal visits, family contact, and family functioning. Crim Justice Behav. 1991;18(3):318-31.

23. National Association for the Care and Resettlement of Offenders (NACRO). Opening the doors: prisoners' families. London: Nacro; 1994.

24. Grinstead O, Faigeles B, Bancroft C, Zack B. The financial cost of maintaining relationships with incarcerated African American 
men: results from a survey of women prison visitors. J Afr Am Men. 2001;6(1):59-69.

25. Braman D. Doing time on the outside: incarceration and family life in urban America. Ann Arbor, MI: University of Michigan Press; 2004.

26. Fishman LT. Women at the Wall: A Study of Prisoners' Wives Doing Time on the Outside. New York: State University of New York Press; 1990.

27. Gabel K, Johnston D. Children of incarcerated parents. Lanham, MD: Lexington Books; 1995.

28. Girshick LB. Soledad women: wives of prisoners speak out. Connecticut and London: Praeger; 1996.

29. Hagan J, Dinovitzer R. Collateral consequences of imprisonment for children, communities, and prisoners. Chicago, IL: University of Chicago Press; 1999.

30. Hairston CF. Family ties during imprisonment: do they influence future criminal activity? Fed Probat. 1988;52(1):48-52.

31. Peelo M, Stewart J, Stewart G, Prior A. Women partners of prisoners. Howard J Criminal Justice. 1991;30(4):311-27.

32. Harris $O$, Miller R. Impacts of incarceration on the AfricanAmerican family. New Brunswick, NJ: Transaction Publishers; 2003.

33. Mauer M, Chesney-Lind M, editors. Invisible punishment: the collateral consequences of mass incarceration. New York: New Press; 2002.

34. Mele C, Miller T, editors. Civil Penalties, Social Consequences. New York: Routledge; 2005.

35. Pattillo M, Weiman D, Western B, editors. Imprisoning America: the social effects of mass incarceration. New York: Russell Sage; 2004.

36. Travis J, Waul M, editors. Prisoners once removed: the impact of incarceration and reentry on children, families, and communities. Washington, DC: Urban Institute Press; 2003.

37. Grinstead O, Faigeles B, Zack B. The effectiveness of peer HIV education for male inmates entering state prison. J Health Educ. 1997;28(6 Suppl):S31-7.

38. Grinstead OA, Zack B, Faigeles B, Grossman N, Blea L. Reducing postrelease HIV risk among male prison inmates: a peer-led intervention. Crim Justice Behav. 1999;26(4):453-65.
39. Grinstead OA, Zack B, Faigeles B. Collaborative research to prevent HIV among male prison inmates and their female partners. Health Educ Behav. 1999;26(2):225-38.

40. Grinstead O, Zack B, Faigeles B. Reducing postrelease risk behavior among HIV seropositive prison inmates: the health promotion program. AIDS Educ Prev. 2001;13(2):109-19.

41. Zack B, Grinstead O, Faigeles B. A health promotion intervention for prison inmates with HIV. In: Bowser B, Mishra S, Reback C, Lemp G, editors. Preventing AIDS: community-science collaborations. Binghamton, NY: Haworth Press; 2004 p. 97-114.

42. Grinstead OA, Faigeles B, Comfort M, Seal D, Nealey-Moore J, Belcher L, et al. HIV, STD, and hepatitis risk to primary female partners of men being released from prison. Women Health. 2005;41:63-80.

43. Wolitski R, Project START Writing Group for the Project START Study Group. Relative efficacy of a multisession sexual risk-reduction intervention for young men released from prisons in 4 states. Am J Public Health. 2006;96(10):1854-61.

44. Comfort M, Grinstead OA, Faigeles B, Zack B. Reducing HIV risk among women visiting their incarcerated male partners. Crim Justice Behav. 2000;27(1):57-71.

45. Grinstead O, Comfort M, McCartney K, Koester K, Neilands T. Bringing it HOME: design and implementation of an HIV/STD intervention for women visiting incarcerated men. AIDS Educ Prev. 2008;20(4):285-300.

46. Long J. Regression models for limited and categorical dependent variables. Thousand Oaks, CA: Sage; 1997.

47. Long J, Friese J. Regression models for categorical dependent data using Stata. College Station, TX: Stata Press; 2002.

48. U.S. Census Bureau. Fact Sheet: 2006-2008 American Community Survey 3-Year Estimates. U.S. Census Bureau web site. http://factfinder.census.gov. Accessed May 29, 2009.

49. Vergidis P, Falagas M. Meta-analyses on behavioral interventions to reduce the risk of transmission of HIV. Infect Dis Clin North Am. 2009;23(2):309-14. 